Doi: $10.22478 /$ ufpb.1983-1579.2020v13n1.51546 http://periodicos.ufpb.br/ojs2/index.php

\title{
INTERCULTURALIDAD COMO DISCURSO EMERGENTE EN LAS REFORMAS CURRICULARES DE LA EDUCACIÓN BÁSICA MEXICANA
}

\author{
INTERCULTURALIDADE COMO DISCURSO EMERGENTE NAS REFORMAS CURRICULARES DA EDUCAÇÃO \\ BÁSICA MEXICANA
}

Ana Laura Gallardo Gutiérrez ${ }^{1}$

Resumen: El trabajo aborda la discusión en torno a la emergencia del discurso de la interculturalidad en las reformas curriculares a la educación básica mexicana de 1993 al 2017. Este análisis retoma como horizonte de intelección la categoría de genealogía en Foucault (1988) en donde las nociones de origen, invención, procedencia y emergencia permiten interpretar el devenir histórico político de dicho discurso. A partir de este planteamiento teórico, se analizan las reformas curriculares en comento, así como el discurso de la educación intercultural como política educativa, centrando la atención en los pliegues y márgenes que supuso esta emergencia, las disputas y polémicas al respecto. La intención es problematizar el supuesto que sitúa a la interculturalidad como un elemento disruptivo para la dimensión epistémica de las reformas curriculares, pero dada la hegemonía (Laclau, 1987) de la lógica de las ciencias de la educación en dichas reformas, su incorporación al curriculum nacional fue débil y eventualmente desplazada.

Palabras clave: educación básica. Interculturalidad. reforma curricular.

\section{INTRODUCCIÓN}

Comprender los procesos de reforma curricular desde posiciones epistemológicas alejadas de la economía y planeación educativa es un imperativo para la región latinoamericana en tanto espacios de creación y reinsurgencia epistémica para construir conocimiento sobre el curriculum en particular y sobre los fenómenos educativos en general.

La lógica tradicional de comprender/construir los problemas curriculares, planear el cambio curricular para atacar tales problemas, diseñar la estructura formal del curriculum y asumir la operación como proceso de aplicación de un nuevo modelo curricular, pertenece a las ciencias de la educación, entendida como dimensión epistémica² de las reformas curriculares neoliberales que datan de 1993 a 2017 en México. De perfil

\footnotetext{
1 Investigador Titular A Doctorado en Pedagogía, UNAM. anag80o@yahoo.com. (01 55) 56226986 ext. 2225. Especialidades: Curriculum intercultural y educación básica, Filosofía, educación e interculturalidad, Investigación en educación ambiental, Teoría pedagógica. Proyectos en proceso Continuidad y disrupción en las políticas curriculares de la educación básica mexicana, 1990-2017. E-mail: anag800@yahoo.com. Orcid: https://orcid.org/0000-0003-1160-7142. ${ }^{2}$ Sánchez Puentes (1984) sitúa dos tipos de dimensiones para comprender cómo opera la construcción del conocimiento
} 
neopositivista, las ciencias de la educación intentan sino eliminar, sí instrumentalizar elementos óntico constitutivos de la educación en tanto objeto de estudio. Las finalidades de la educación, así como la densidad de los procesos identificatorios constitutivos de la subjetividad tanto de alumnos como de profesores mediante una propuesta curricular, son atendidos de manera marginal o de plano excluidos para comprender los procesos de reforma curricular. De ahí que sea relevante mostrar el cambio curricular como un proceso complejo, diverso y con múltiples capas, como señala Popkewtiz (1991, p.16), "es importante comprender la reforma escolar como una relación entre el saber, la estructura y el poder”.

En este marco, surge la pregunta por el discurso de la educación intercultural y la interculturalidad en las reformas curriculares de la educación básica mexicana, en tanto narrativa que intenta erosionar el referente cultural del curriculum de la educación básica, en sus límites y alcances.

Intento mostrar (en el sentido de Wittgenstein) que tales alcances son magros, pero instalaron una discusión epistémico ontológica en el curriculum de la educación básica nacional de gran calado, porque la interculturalidad cuestiona de manera central la conformación nuclear no sólo del curriculum de la escuela básica, sino el carácter nacional del sistema educativo mexicano ¿Quiénes son/somos la nación mexicana? Lo intercultural trae a colación entonces, la conformación multicultural del país, con especial énfasis en los pueblos originarios y afromexicanos previos a la conformación del Estado Nación, previos a la conformación de la mexicanidad que da sentido al curriculum nacional.

Para lograr lo antes descrito, dedicaré un apartado a plantear la noción de emergencia en NietzcheFoucault como elemento epistémico central para comprender la aparición del discurso de la interculturalidad en las reformas, después será preciso dibujar a grandes rasgos los distintos momentos de reforma curricular que interesa discutir, para observar las continuidades y discontinuidades; la institucionalización o desplazamiento de la emergencia de dicho discurso, en una tercera sección abordaré como segundo gran componente de la emergencia, algunos elementos significativos en la historia de la educación indígena como campo de procedencia, para finalmente cerrar con algunas reflexiones en torno al carácter disruptivo del discurso de la interculturalidad en el curriculum de la educación básica nacional.

\section{EMERGENCIA Y DISCURSO EN LA REFORMA CURRICULAR}

La noción de emergencia se retoma de la discusión en torno a las categorías de origen, verdad y genealogía planteadas por Nietzche en su Genealogía de la Moral del año 1887 (2011), la cuales recupera y problematiza en 1971 Michel Foucault, en su ensayo Nietzche, la genealogía, la historia (1988), mismas que impactan en distintas obras del autor, en particular en La verdad y las formas jurídicas de 1978 (1996), donde volverá sobre el asunto de la emergencia en torno a las prácticas judiciales como prácticas de saber poder. Esta racionalidad genealogista le permitirá la construcción de sus obras posteriores.

Para Nietzche (2011) la pregunta por el origen de las costumbres morales de su época lo llevan a plantear la discusión entre el ursprung como origen ligado a una develación teogónica de la moral buscada desde Platón y a plantear, por otro lado, la idea de invención (erdinfung), como artificio o artimaña, práctica perniciosa sobre la aparición de las reglas morales que contravienen el origen como develación metafísica de lo bueno y por asociación de la verdad.

en las ciencias sociales y permite en este caso, comprender la forma en que operan las ciencias de la educación ligadas a una dimensión epistémica positivista. Tal dimensión epistémica refiere a la lógica desde la cual se piensa un objeto de estudio, al posicionamiento ontológico y político que se asume en torno a la noción de realidad, de conocimiento, la relación sujeto-objeto y el método de conocimiento. Por su parte la segunda dimensión, es la teórica. La teoría es la resultante de la práctica epistémica, en el sentido de producir conocimiento contextual sobre los fenómenos. En este sentido, la dimensión epistémica de las ciencias de la educación, mediante las teorías de la economía de la educación, ha situado el problema de las reformas curriculares como un asunto de "mala aplicación", como si fuera un proceso lineal y predecible, sin observar que es un proceso relacional, en donde los limites son anexactos (Arditi,1995) y los puntos en donde interactúan las estructuras sociales y los sujetos del curriculum, son difusos, opacos, no lineales.

Rev. Espaço do Currículo (online), João Pessoa, v.13, n.1, p. 4-16, jan/abr. 2020. 
ISSN 1983-1579

Doi: 10.22478/ufpb.1983-1579.2020v13n1.51546

http://periodicos.ufpb.br/ojs2/index.php

Al comienzo de la Genealogía de la moral, se establece como problema central del texto la discusión sobre los prejuicios morales y el origen de los mismos, esta meta se va complejizando a medida que la idea de origen como esfuerzo por encontrar la esencia exacta, el momento fundacional inmóvil; se aleja. Foucault dirá al respecto, que esta búsqueda en Nietzche es tratar de "encontrar lo que ya existía, el eso mismo de una imagen exactamente adecuada a sí misma” (1988, p.17-18).

Por su parte, el erdinfung ligado a la invención, lo relaciona con el comienzo histórico, la opacidad y circunstancia en tanto condiciones de posibilidad de los prejuicios morales. La intención es alejarse de la idea de origen como algo natural, evolutivo, de la fecha y esencia de los fenómenos. Para afirmar que es una construcción azarosa y por tanto, no existe el comienzo perfecto; al contrario, la tarea de la genealogía como metódica, acude a "localizar la singularidad de los acontecimientos, fuera de toda finalidad monótona" (Foucault, 1988, p.12).

Queda entonces la tarea por establecer este análisis como un acercamiento genealógico sobre el discurso de la interculturalidad pues no se busca el origen escencializado de dicho discurso como una secuencia lineal y progresiva de acontecimientos. Hago esta aclaración porque en distintos foros y trabajos sobre la historia de la educación intercultural en la región latinoamericana, se ha establecido una especie de purismo sobre las condiciones de posibilidad en la emergencia de la interculturalidad y para el caso de México, esta actitud purista se recrudece3.

En oposición a esta actitud, se intenta prestar atención a las opacidades, aparentes contradicciones, reconocer los acontecimientos de la historia de la educación intercultural, "sus sacudidas, vacilantes victorias, las derrotas mal digeridas que explican los comienzos, los atavismos y las herencias" (Foucault, 1988:26), su devenir.

Para Nietzche (2011) en su Genealogía, erdinfung, está asociado con el término Herkfunt o procedencia, mucho más cercano al objeto propio del ejercicio genealógico en el sentido de pertenencia a un grupo, pero no se trata de buscar la procedencia como asociación directa a otros o semejanza con, o linaje, sino descubrir las marcas o huellas específicas que al relacionarse de manera compleja muestran al fenómeno en cuestión, Foucault señala al respecto:

La procedencia permite también reconocer bajo el aspecto único de un carácter, o de un concepto, la proliferación de los acontecimientos a través de los cuales (gracias a los cuales, contra los cuales) se han formado. La genealogía no pretende remontar el tiempo..., su tarea no es mostrar que el pasado está ahí, bien vivo en el presente... Nada que semeje a la evolución de una especie, al destino de un pueblo... al contrario, conservar lo que ha sucedido en su propia dispersión: localizar sus accidentes, las mínimas desviaciones... los malos cálculos que han dado nacimiento a lo que existe y es válido para nosotros (1988, p. 26-27).

El trabajo de la genealogía es mostrar las huellas, la articulación entre la historia inscrita (que arruina -

\footnotetext{
${ }^{3}$ Me refiero a las afirmaciones de Baronet y Medina (2013) durante la presentación del libro "Autonomía y Educación Indígena. Las escuelas zapatistas de la Selva Lacandona de Chiapas, México" (Quito: Abya-Yala, 2012) en la Facultad de Filosofía y Letras de la UNAM, en la que se escandalizan sobre el origen neoliberal y de derecha de este discurso como una herencia a rechazar o que deslegitima los esfuerzos de las reformas curriculares al respecto. También está el ejemplo de lo sucedido en la presentación del Estado del conocimiento área 12 multiculturalismo y educación, presentado en el XII Congreso Nacional de Investigación Educativa en Guanajuato, México, durante noviembre de 2013, en el cual se advertía por parte de la comentarista del trabajo, que dicho estado de conocimiento se enmarcaba en una especie de endogamia político-educativa, que llevaba a aseveraciones maniqueas como "hay una interculturalidad buena y una mala". En estos y otros casos, la tentación de ubicar la interculturalidad como un discurso puramente gubernamental sostengo-, se enmarca en la búsqueda por el origen-ursprung al que Nietzche refiere y no por un acercamiento genealógico o de la invención erdinfung, que puede observarse es incómodo y truculento.
} 
dice Foucault-) a los cuerpos, a los discursos a la interculturalidad como discurso que irrumpe las reformas curriculares.

Finalmente, para Foucault (1988) el esquema genealógico en Nietzche está completo con la categoría de Entstehung la cual designa a la noción de emergencia, el punto de surgimiento o aparición, el cual solo es posible como campo de fuerzas, como red compleja de las relaciones de saber poder. Esto es, las luchas que tienen lugar en el marco de la emergencia del discurso de la interculturalidad y la educación intercultural, así como su posicionamiento en las reformas curriculares. La emergencia refiere en este caso a la entrada disruptiva, el impulso por el que saltan a primer plano una u otra tendencia para comprender las formas en que se asume lo intercultural en las reformas.

Mientras la procedencia sitúa las huellas de la historia en el acontecimiento, la emergencia designa un lugar de enfrentamiento, un campo de lucha no cerrado que permite el surgimiento en su conexión con dichas huellas. "Nadie es responsable de una emergencia, ni nadie puede vanagloriarse de ella; siempre se produce en el intersticio" Foucault (1988, p.38).

Por lo hasta ahora dicho, es pertinente ahora comenzar con el ejercicio específico que suponen estas categorías para el objeto de estudio planteado. Como prolegómeno de tal propósito, es importante situar elementos en torno a la procedencia de las reformas curriculares de los últimos 30 años en México para situar algunas huellas e inscripciones que nos den pista sobre la emergencia del discurso de la interculturalidad en la educación básica mexicana.

\section{RELACIONES DE SABER PODER EN LA CONFIGURACIÓN DE LAS REFORMAS CURRICULARES A LA EDUCACIÓN BÁSICA MEXICANA}

Aunque pueda parecer ocioso, es preciso comenzar este apartado aclarando la noción de curriculum, para reafirmar que no puede reducirse a la idea de plan de estudios. En este sentido, el curriculum se entiende como proyecto político (De Alba, 1991) y dispositivo de escolarización el cual se configura hacia finales del siglo XVIII en Europa y se consolida a través de los sistemas educativos de los Estados Nación modernos. En el caso de América Latina en general y de México en particular, el curriculum como dispositivo y política educativa también emerge en el marco de la constitución de los Estados Nación para contribuir en la conformación de las identidades nacionales recién creadas. Esta huella o impronta es relevante porque muestra la capacidad constitutiva de la subjetividad del dispositivo y cómo se impone sobre la diversidad cultural, étnica y lingüística del país.

Por ejemplo, en el caso de México, la Constitución de 1857 estableció con las libertades de asociación, petición y tránsito, la supresión del monopolio de la iglesia sobre la educación. En el Art. $3^{\circ}$ esta concepción se sostiene con firmeza: "La enseñanza es libre; la ley determinará qué profesiones necesitan título para su ejercicio y con qué requisitos se debe expedir" (Juárez, 1859). En consecuencia, en 1861 el nuevo plan de estudios introdujo las cátedras de instrucción cívica e historia patria para el nivel elemental debido a la necesidad evidenciada por la guerra de formar ciudadanos leales a la patria y no al clero, ello implicó entonces la institucionalización del sistema en tanto ley que fija y condensa un discurso educativo a partir de la hegemonía de la pedagogía liberal como práctica que marginó otros discursos, en este caso el indígena y afromexicano, los cuales a su vez, posibilitaron su propia existencia.

Esta legalización y desarrollo (Puiggrós, 1995) de los sistemas educativos latinoamericanos alcanza su punto máximo en el siglo XX. En este devenir, la educación primero elemental y luego básica porta de manera central esta carga nacionalista que a manera de huella, se mantiene hasta nuestros días en condiciones críticas, pues la conformación de lo mexicano como fundante del curriculum de la educación básica está emplazado socialmente.

De acuerdo a los estudios curriculares (Díaz Barriga y García Garduño, 2011; Furlán, 1997; Orozco, 2015), el curriculum en México al igual que en el resto de América Latina, importó los productos del mercado curricular estadounidense, desde las primeras décadas del siglo XX y con mayor fuerza a partir de los años 
ISSN 1983-1579

Doi: 10.22478/ufpb.1983-1579.2020v13n1.51546

http://periodicos.ufpb.br/ojs2/index.php

sesenta. La lógica tayleriana introduce a las ciencias de la educación como dimensión epistémica del curriculum y se implantó desde la legitimidad del método científico positivista, desde la racionalidad instrumental como la llamó Habermas en Conocimiento e interés (1982).

Esta afirmación refiere a la polémica sobre el estatuto científico del conocimiento educativo ligado a la metódica positivista y neopositivista (de Alba, 1990) para constituir la unidad disciplinar de las distintas expresiones de las ciencias que "acuden" al fenómeno educativo. Es en este momento epistemológico del campo educativo, que la sociología funcionalista y la psicología conductista fundamentan teórica y metodológicamente una nueva unidad disciplinar.

El efecto que esta fórmula trajo fue una suerte de aplicación. El efecto de la preposición "de" (sociología de la educación p. ej.) a decir de Follari (1990), generó un alejamiento teórico, epistemológico y metodológico de los campos originarios. Dicho de otro modo, no se puede considerar a la economía o a la antropología como siendo "para la educación" puesto que el desarrollo de esos campos es autónomo al de las ciencias de la educación. Este alejamiento de las ciencias de origen implicó el empobrecimiento del campo educativo; "escindir a las ciencias de la educación de su tronco teórico conceptual, ha llevado a la aparición de pálidas versiones de los avances y niveles de rigor que se dan en las disciplinas originales" (Follari, 1990, p. 69-70).

La crítica contrahegemónica a esta racionalidad instrumental de las ciencias de la educación, tuvo lugar en el ámbito curricular a través del intenso y productivo debate entre la tecnología educativa y los estudios críticos sobre el curriculum, en los años setenta y ochenta del siglo pasado en México. Se acuñaron categorías teóricas y operativas para la creación de nuevos proyectos curriculares situados en su mayoría, para los niveles medio superior y superior ${ }^{4}$, en el caso de la educación básica eso no sucedió. La lógica de las ciencias de la educación en el ámbito curricular de este nivel educativo se ha mantenido prácticamente intacta, aunque con la llegada del primer gobierno de centro izquierda al país en 2018, la retórica apunta a una mirada más cercana al registro político ontológico de lo educativo (Buenfil,1993) y en específico, del curriculum como dispositivo o práctica de escolarización tendiente a reestablecer el lazo comunitario dañado por la corrupción, el narcotráfico, entre otros grandes problemas sociales que se traducen y adquieren cariz propio en las escuelas del nivel básico.

Entonces, es posible observar en las reformas curriculares que datan de 1993 a la fecha, la lógica de las ciencias de la educación o racionalidad instrumental, la cual se decanta en al menos dos paradigmas que han avanzado de manera compleja, a manera de capas, en la definición de la estructura formal del curriculum de la educación básica mexicana.

Uno es el paradigma de la piscología de la educación, el cual funge como campo que detenta el saber legitimado en torno a la comprensión del aprendizaje, como un proceso controlado y verificable. Esta visión se amalgamó a las teorías provenientes, también de la psicología, sobre el constructivismo sociocultural del aprendizaje, en específico en torno a la lecto escritura. El aprendizaje, desde estas corrientes y sus variaciones, aluden a un proceso progresivo entre lineal y complejo, en una suerte de pliegues conceptuales que a primera vista pueden ser contradictorios pero conviven en el plan y programas nacionales (Gallardo, 2014).

\footnotetext{
${ }^{4}$ Orozco (2015, p.122) señala al respecto "En México, por citar un caso, esto se observó con propuestas curriculares nuevas como el Plan A-33 de la carrera de medicina con un enfoque de medicina social, y la creación del Colegio de Ciencias y Humanidades (bachillerato) en la Universidad Nacional Autónoma de México, el proyecto de UniversidadPueblo o de las universidades democráticas, críticas y populares en Guerrero, Puebla, Chapingo o Zacatecas, que se asumieron como tales, pero otras también muy destacadas Sinaloa, Oaxaca y otras tantas. Habrá que citar también la apertura de la Universidad Autónoma Metropolitana (UAM) y su propuesta modular a mediados de los años setenta, por citar algunas elaboraciones curriculares innovadoras con sentido crítico social”.
} 
En esta lógica, el aprendizaje es progresivo esto es, como la construcción de andamiajes que van de lo sencillo a lo complejo, de lo particular a lo general y que se convierten en criterios para organizar la evaluación, la cual también se ha amalgamado, desde las tendencias más ligadas al control y la verificación, hasta la corriente llamada evaluación formativa, donde se complejiza o sofistica la posibilidad de saber qué pasa con los alumnos, si aprenden o no y qué aprenden. Muestra de ello son las rúbricas y actividades de evaluación que intentan paliar los efectos de los exámenes dentro del aula, aunque las pruebas estandarizadas sigan teniendo un carácter homogeneizante que no de construcción común del aprendizaje.

El segundo paradigma es el de la filosofía de la educación, situado específicamente en el componente de las finalidades del curriculum de la educación básica. Tanto para Taba (1976) como Tayler (1973), la definición de las finalidades de un modelo curricular se construye con base en los objetivos de aprendizaje a alcanzar y generalmente se decantan en el perfil de egreso, dicho perfil se elabora con base en el análisis de las necesidades sociales y los sujetos. El análisis es lógico deductivo e intencionadamente se aleja de asumir las necesidades sociales como el registro político de una propuesta curricular. Esta visión es clara en los distintos procesos de reforma, por lo menos de los últimos 30 años, en los siguientes párrafos podrá apreciarse cómo se entienden las necesidades sociales en tanto finalidades de las reformas curriculares en comento, tomando como base la estructura formal del curriculum.

\title{
3.1 Reforma curricular de 1993. Sexenios salinistas (1988-1993) y zedillista (1994-2000)
}

En mayo de 1992, se firmó el Acuerdo Nacional para la Modernización de la Educación Básica y la Secretaría de Educación Pública inició la última etapa de la transformación de los planes y programas de estudio (SEP,1992).

En éste se indica que una de las acciones principales en la política del gobierno federal es mejorar la calidad de la educación, obedeciendo a prioridades claras:

\begin{abstract}
La educación básica impulsa la capacidad productiva de una sociedad y mejora sus instituciones económicas, sociales, políticas y científicas, puesto que contribuye decisivamente a fortalecer la unidad nacional y a consolidar la cohesión social, a promover una más equitativa distribución del ingreso, a fomentar hábitos más racionales de consumo, a enaltecer el respeto a los derechos humanos, en particular el aprecio a la posición de la mujer y de los niños en la comunidad, y a facilitar la adaptación social al cambio tecnológico. Además, una buena educación básica genera niveles más altos de empleo bien remunerado, una mayor productividad agrícola industrial, y mejores condiciones generales de alimentación y de salud, y actitudes cívicas más positivas y solidarias (SEP,1992, p.4).
\end{abstract}

En 1994, el gobierno zedillista continuó las premisas básicas del Acuerdo Nacional para la Modernización Educativa, en el Programa Sectorial de Educación no hay mayores cambios y la reforma curricular prospera, generando condiciones para la reorganización constante de las asignaturas de español y matemáticas, pero sobre todo de la reestructuración de la asignatura de educación cívica, la cual devino en la asignatura de formación cívica y ética misma que sigue vigente hasta hoy.

Esta innovación curricular es importante por dos razones: la primera porque supuso la reactivación del debate sobre la laicidad de la educación, al incorporar contenidos de ética y su asociación con contenidos de moral o religión ${ }^{6}$ y su alejamiento del carácter meramente cognitivo o academicista del curriculum de la educación básica, aun con la incorporación de nuevos enfoques en las didácticas específicas en otras asignaturas, los objetos de estudio y aprendizaje no variaron mucho (SEP, 1993).

Y en concordancia con lo anterior, la segunda razón implica que un cambio curricular de esta naturaleza trastocó -discretamente- la lógica curricular antes descrita. Este efecto es documentado por Díaz Barriga (2005) vía el análisis de los temas transversales, enfocándose en la formación de valores, para señalar que su

${ }^{5}$ Se refiere a los ex presidentes Carlos Salinas de Gortari y Ernesto Zedillo Ponce de León.

${ }^{6}$ Véase el estudio al respecto de Pablo Latapí (1999), La moral regresa a la escuela. 
ISSN 1983-1579

Doi: 10.22478/ufpb.1983-1579.2020v13n1.51546

http://periodicos.ufpb.br/ojs2/index.php

inserción supone traer los debates sociales actuales a una estructura curricular rígida como lo es el curriculum nacional centralizado de México, que tiende a ser impermeable al contexto social con el cual se relaciona en la dimensión del curriculum vivido ${ }^{7}$.

\subsection{Reforma curricular de 2011. Sexenios foxista y calderonista ${ }^{8}$}

Con la entrada del nuevo gobierno en el año 2000, la derecha asume una continuidad con la política curricular impulsada en el Acuerdo Nacional para la Modernización de 1992. Después de reformarse la primaria como componente esencial del nivel básico, se continuó con el cambio curricular en preescolar (2004) y después en 2006 para el tramo de la secundaria. La educación básica comprende así, 12 años de instrucción divididos en tres tramos: tres años de preescolar, seis años de primaria y tres de secundaria.

En ambos sexenios la calidad se sitúa como bisagra para la modernización y el desarrollo humano, señalándose una referencia clara que engarza el sentido de la calidad a la competitividad y con ello se establece como finalidad la relación educación-mercado de trabajo.

[...] En 2025, el Sistema Educativo Nacional estará organizado en función de los valores de equidad y calidad, ofrecerá a toda la población del país una educación pertinente, incluyente e integralmente formativa, que constituirá el eje fundamental del desarrollo cultural, científico, tecnológico, económico y social de México (SEP, 2006, p.85).

Por su parte la reforma de 2011 señalará:

[...] La exigencia de una educación de calidad ha de ser más radical y urgente en las escuelas donde se forman los alumnos provenientes de los sectores más desprotegidos y vulnerables. Para ellos la escuela es, muchas veces, la única oportunidad de prepararse para un mejor futuro y romper así el vínculo que liga la pobreza con la marginación y la ignorancia.

En la sociedad del conocimiento, la competitividad de los países depende, en buena medida, de la fortaleza de sus sistemas educativos y de su capacidad de generar y aplicar nuevos conocimientos.

México debe hacer de la educación, la ciencia y la tecnología los puntales de su desarrollo (SEP, 2011, p.10).

Los significantes calidad y competitividad para el mercado de trabajo operan como horizontes de la sociedad para la que forme la educación básica, aludiendo a los cambios en el tipo de economía globalizada en la que vivimos y con ello la necesidad de alinearse a los estándares internacionales. Esta mirada sobre el desarrollo y el papel de la educación si bien es congruente entre los objetos analizados, es necesario interrogarse por el impacto en el curriculum vivido de estas máximas de la relación educación mercado, ¿en las escuelas se caminó hacia allá? Esa definición de necesidades, después de casi 10 años ¿Fue pertinente? ¿Qué consecuencias en el aprendizaje trajo?

Existen otros registros que evidencian la lógica de las ciencias de la educación como procedencia y huella de las reformas curriculares, se muestran estas dos para situar la arena de la contienda en tanto fuerzas que actúan como posibilidad/imposibilidad de la aparición de discurso de la interculturalidad en el curriculum de la educación básica en el año 2000.

7 Se considera que en el contexto hispanoamericano, la Ley de Ordenación General del Sistema Educativo de 1990 en España, impactó en las reformas educativas de la región, entre otros aspectos en lo referente a la incorporación formal de temas transversales al curriculum de la educación básica, incluidos desde la perspectiva de la formación valoralactitudinal, de ahí que en el año 2000 encontráramos afirmaciones en México como que la educación intercultural era una educación en valores intentando mantenerla en el registro de lo actitudinal-psicología de la educación (Schmelkes, 2004).

${ }^{8}$ Se refiere a los expresidentes Vicente Fox Quezada (2000-2006) y Felipe Calderón Hinojosa (2007-2012). 
Durante estos dos sexenios, es que esta narrativa, impulsada por la contienda de varios acontecimientos, logró su incorporación. Aquí es preciso recuperar la huella de la entrada de la asignatura de formación cívica y ética mencionada líneas arriba, porque esa entrada a nivel curricular fue condición de posibilidad del discurso intercultural, pero al contener un sentido social más intenso que formación cívica y ética ${ }^{9}$, provocó mayores tensiones a la estructura curricular y ello llevó a su imposibilidad como eje transversal en el curriculum de la educación básica.

Para explicar lo anterior con mayores elementos, es preciso continuar con el análisis de la procedencia del discurso intercultural en el curriculum de la educación básica, pero ahora desde la historia de la educación indígena mexicana para que, teniendo las huellas de procedencia y las fuerzas en tensión, se despliegue el supuesto hasta ahora planteado: la interculturalidad es un discurso disruptivo en la lógica hegemónica del curriculum de la educación básica y en la contienda y lucha por la sobredeterminación curricular (De Alba, 2002) que apunta a la dimensión epistémica o lógica de la tradición curricular mexicana, de ahí su imposibilidad.

\section{INTERCULTURALIDAD Y EDUCACIÓN INTERCULTURAL EN LAS REFORMAS CURRICULARES}

La conformación del sistema educativo mexicano desde su nacimiento en el siglo XIX, estableció un solo referente cultural como sujeto pedagógico: el de la mexicanidad-mestiza. Este referente alude a una cultura homogénea como identidad nacional, al español como lengua dominante y la ciencia positivista como canon epistemológico de las ciencias escolares. Esta triada ha sostenido y por tanto excluido otras culturas, lenguas, conocimientos y saberes como las de los pueblos originarios y los pueblos afromexicanos.

En este sentido, la educación indígena nace como un apéndice de dicho sistema educativo, estableciendo así una relación de inclusión vía la exclusión (en el sentido de Laclau, 1987) del referente cultural que organiza la educación nacional.

Aludiendo a una aproximación genealógica sobre la pertenencia-emergencia de la interculturalidad, se puede afirmar que es un discurso que irrumpe y se excluye de las reformas curriculares en el arco histórico de 2004 a 2017 como se ha descrito arriba. Las huellas o sentidos de pertenencia tienen sus raíces en la historia misma de la relación entre el Estado mexicano y sus pueblos originarios, que en lo concerniente a lo educativo, lo cual se puede organizar temporalmente en cuatro grandes periodos.

La primera etapa (1940-1960) corresponde a la política de castellanización derivada de una estrategia del indigenismo oficial. El objetivo fue integrar social y culturalmente a los pueblos indígenas dentro de la sociedad mexicana, mediante un proceso de aculturación y homogeneización. El segundo momento corresponde a las políticas de educación bilingüe y bicultural, impulsadas por intelectuales indígenas en la década de los setenta. Esta generación de políticas educativas estableció la necesidad de conformar un subsistema de educación indígena en donde se aprenda la lengua y cultura originaria a la par que el español y la cultura nacional. La intención devino en muchos casos, en la inclusión de lo indígena de manera idealista y escencializada, por lo que la educación nacional continuó intacta en su núcleo cultural y en consecuencia se profundizaron las desigualdades entre el subsistema de educación indígena y el sistema educativo nacional (1960-1993).

Un tercer momento puede ubicarse en relación con el levantamiento del Ejército Zapatista de Liberación Nacional ${ }^{10}$ en 1994 en Chiapas y la presión -que en general- impulsó el movimiento indígena

\footnotetext{
${ }^{9}$ Esta asignatura se considera como cambio discreto a la lógica curricular dominante, porque el componente cognitivoactitudinal de esta materia imperó por sobre el ético político (Coll, Pozo, Sarabia y Valls 1994) que de acuerdo a Díaz Barriga (2005), es aquél que está en el registro del aprendizaje de los valores.

${ }^{10}$ Movimiento indígena que surge de la reorganización de los grupos que durante los años setenta en México, resistieron la persecución y represión (guerra sucia) con el movimiento indígena mexicano, ampliando la agenda por el reconocimiento de los derechos y culturas indígenas en el país. Con sus grises y opacidades han consolidado en estos 26 años, un sistema autogestivo de organización social y política que muestra cómo desde la cosmovisión de los pueblos
}

Rev. Espaço do Currículo (online), João Pessoa, v.13, n.1, p. 4-16, jan/abr. 2020. 
ISSN 1983-1579

Doi: 10.22478/ufpb.1983-1579.2020v13n1.51546

http://periodicos.ufpb.br/ojs2/index.php

mexicano, pues abrió paso a las políticas de educación intercultural bilingüe (EIB). Este hecho se articuló además al discurso de varios organismos internacionales que planteaban la necesidad del reconocimiento de la diversidad étnica, cultural y lingüística, principalmente el Banco Mundial, signando el futuro con dos grandes tendencias para la EIB en nuestro país: por un lado la acción política de los gobiernos entre 2000 y 2012 que planteó la necesidad de un giro en la forma de relación de las políticas, afirmando que la EIB no es sólo para los indígenas sino para todos los habitantes de la nación. Bajo su manto, se emprendieron acciones de gran calado como las universidades interculturales, el Instituto Nacional de Lenguas Indígenas o la Coordinación de Educación Intercultural y Bilingüe.

En este marco interesa señalar que las reformas curriculares de 2004 preescolar, 2006 secundaria, 2009 primaria y 2011 articulación de los tres niveles; reflejaron y materializaron el discurso de la educación intercultural para todos y no solo para los pueblos indígenas. Se incorporaron contenidos a las asignaturas ya establecidas, en particular -y como era de esperarse-, en la materia de formación cívica y ética, en biología, español, matemáticas y otras tantas. Además, en 2005 se implementó la creación de una asignatura de lengua indígena para secundaria. Ambas innovaciones curriculares tuvieron su punto máximo en la reforma del 2006 con la Publicación del “Acuerdo por el que se reforma la educación secundaria” (SEP, 2006a), donde esta asignatura de lengua indígena tenía carácter obligatorio.

Durante la reforma curricular de 2009 y luego en la de 2011, esta entrada tan intensa se fue debilitando, hasta quedar solamente en la retórica de la estructura formal del curriculum, esto es, en el plan de estudios, el perfil de egreso, pero sin tener un eco en las materias y contenidos que conformaron el mapa curricular ${ }^{11}$. También en 2011 la asignatura de lengua indígena quedó como asignatura optativa por lo que su operación disminuyó hasta prácticamente desaparecer. Aunque en la última reforma de 2017 se reportaron cerca de 400 escuelas en comunidades indígenas hablantes en donde todavía se imparte ${ }^{12}$.

En el sexenio 2013-2018 esta situación no cambió, al contrario, el desplazamiento del discurso de la interculturalidad en las reformas curriculares se consumó en 2017, mediante la agrupación de "los diferentes", interpretando la diversidad como problema, mediante el discurso de la inclusión educativa. La tentación por la universalización a través del carácter nacional del curriculum es una fuerza que sigue fundamentando y con ello dando sentido al modelo educativo de la educación básica desde sus orígenes en el siglo XIX, el cual se mantiene hasta nuestros días como un elemento constitutivo de la conformación de la identidad nacional en tanto finalidad heredada.

El discurso de la inclusión educativa en las políticas curriculares tomó como base las discusiones que en el campo de la discapacidad se han desarrollado, articulándolas al discurso de la equidad y la observancia de la educación como derecho exigible a los estados, por lo que desmontar su lógica es harto complejo, debido a que lo intercultural se subsume a la inclusión y al hacerse presente desde su invisibilidad pierde fuerza.

Ante la creciente negativa y cerrazón de ampliar y mejorar los programas educativos interculturales gubernamentales existentes, la acción política de la sociedad civil impulsó de manera innovadora la necesidad de construir políticas desde otras bases, en donde los sujetos de atención se desplazan a ser agentes del diseño y puesta en marcha de tales políticas curriculares interculturales.

Estas dos tendencias: la de acción gubernamental y la de la acción de la sociedad civil se han ido distanciando cada vez más, el efecto de esta creciente tensión lleva a los proyectos alternativos, muchas veces por decisión propia, a los márgenes del curriculum nacional, no contienden por erosionar o irrumpir el

indígenas se puede reorganizar el orden social frente al neoliberalismo,.

${ }^{11}$ Consúltese KREISE, Maike. El enfoque intercultural en el currículo de telesecundaria-Elementos para una reflexión crítica. En Sinéctica, Revista Electrónica de Educación, 2016, redalyc.org

${ }^{12}$ Este dato lo aportó la actual directora del área de desarrollo del curriculum intercultural, en febrero de 2019. 
carácter nacional de la educación básica por lo que la posibilidad de un cambio estructural se ve cada más lejana.

Esta radicalización de los proyectos alternativos ha llevado a una cierta distorsión de la procedencia de la educación intercultural, para mantener un halo purista sobre la buena y la mala educación intercultural, debido al fracaso en términos de política educativa. La sociedad civil a través de la valoración que los académicos involucrados en esta postura han dado al devenir de la educación intercultural del 2000 a la fecha, es el ejemplo. Ya en la nota a pie número dos de este texto, señalé que las declaraciones de Baronet y Medina en 2013 critican, minimizan e incluso reorganizan la relación huella entre el Movimiento zapatista y la educación intercultural. Al respecto, los Acuerdos de San Andrés Larráinzar pactados entre el gobierno federal y los zapatistas en 1996 señalan:

Se ratifica el derecho a la educación bilingüe e intercultural de los pueblos indígenas. Se establece como potestad de las entidades federativas, en consulta con los pueblos indígenas, la definición y desarrollo de programas educativos con contenidos regionales, en los que deben reconocer su herencia cultural. Por medio de la acción educativa será posible asegurar el uso y desarrollo de las lenguas indígenas, así como la participación de los pueblos y comunidades de conformidad con el espíritu del Convenio 169 de la OIT (GOBIERNO FEDERAL, 1996, p. 8).

Por lo que dice el Programa sectorial del año 2000 (SEP, 2000), el discurso de la educación intercultural se presenta con mucha fuerza, es el sexenio en donde más impulso tiene, como ya se ha dicho en párrafos anteriores y aunque se comprende la frustración del fracaso, no puede negarse que el impulso político del zapatismo influyó de manera central en ese programa sectorial, en las acciones y programas desarrollados. Esta falsa polémica es muy interesante para la genealogía del discurso de la educación intercultural, porque muestra los pliegues, opacidades, desacuerdos en su devenir, y son parte de su historia, de su emergencia, estemos de acuerdo o no con la direccionalidad política que ha tenido tal devenir.

Con la llegada del nuevo gobierno en 2018, el discurso de la educación intercultural y de la interculturalidad se ha reactivado, por ahora a nivel de los cambios en la Constitución Política y en las Leyes Secundarias, el proceso de reforma curricular está en marcha y no se han develado muchos datos al respecto.

El marco de la nueva política educativa se denomina Nueva Escuela Mexicana y se han hecho cambios en los Artículos $2^{\circ}$ y $3^{\circ}$ de la Constitución Política de los Estados Unidos Mexicanos, los cuales señalan:

Art. $2^{\circ}$

La Nación tiene una composición pluricultural sustentada originalmente en sus pueblos indígenas que son aquellos que descienden de poblaciones que habitaban en el territorio actual del país al iniciarse la colonización y que conservan sus propias instituciones sociales, económicas, culturales y políticas, o parte de ellas.

La conciencia de su identidad indígena deberá ser criterio fundamental para determinar a quiénes se aplican las disposiciones sobre pueblos indígenas.

Son comunidades integrantes de un pueblo indígena, aquellas que formen una unidad social, económica y cultural, asentadas en un territorio y que reconocen autoridades propias de acuerdo con sus usos y costumbres" (SEGOB, 2019).

Art. $3^{\circ}$

“[...] Los planes y programas de estudio tendrán perspectiva de género y una orientación integral, por lo que se incluirá el conocimiento de las ciencias y humanidades: la enseñanza de las matemáticas, la lecto-escritura, la literacidad, la historia, la geografía, el civismo, la filosofía, la tecnología, la innovación, las lenguas indígenas de nuestro país, las lenguas extranjeras, la educación física, el deporte, las artes, en especial la música, la promoción de estilos de vida saludables, la educación sexual y reproductiva y el cuidado al medio ambiente, entre otras [...] 
ISSN 1983-1579

Doi: 10.22478/ufpb.1983-1579.2020v13n1.51546

http://periodicos.ufpb.br/ojs2/index.php

[...] c) Contribuirá a la mejor convivencia humana, a fin de fortalecer el aprecio y respeto por la naturaleza, la diversidad cultural, la dignidad de la persona, la integridad de las familias, la convicción del interés general de la sociedad, los ideales de fraternidad e igualdad de derechos de todos, evitando los privilegios de razas, de religión, de grupos, de sexos o de individuos...

[...] e) [...] En los pueblos y comunidades indígenas se impartirá educación plurilingüe e intercultural basada en el respeto, promoción y preservación del patrimonio histórico y cultural $[\ldots]$

[...] g) Será intercultural, al promover la convivencia armónica entre personas y comunidades para el respeto y reconocimiento de sus diferencias y derechos, en un marco de inclusión social [...] (SEGOB, 2019)

Por su parte, en el Plan Nacional de Desarrollo, en su Eje 2. Bienestar, Objetivo 2.2 Garantizar el derecho a la educación laica, gratuita, incluyente, pertinente y de calidad en todos los tipos, niveles y modalidades del Sistema Educativo Nacional y para todas las personas, se señala las siguientes estrategias que aluden directamente al discurso de la educación intercultural:

2.2.1 Asegurar el acceso y permanencia en la educación, ofreciendo oportunidades educativas que tengan como eje principal el interés superior de las niñas, niños, adolescentes, priorizando a las mujeres, los pueblos indígenas y a los grupos históricamente discriminados.

2.2.3 Revisar los planes y programas de estudio en todos los tipos y niveles del Sistema Educativo Nacional, promoviendo la educación sostenible, artística, científica, tecnológica, financiera, ambiental, sexual, cívica, indígena, intercultural y comunitaria, que garanticen el derecho a la igualdad de género, la no discriminación y la eliminación de la violencia (PND, 2019).

No existen muchos elementos para aventurar análisis profundos, tan solo señalar que en el artículo tercero la referencia de lo intercultural se advierte más centrado en el ámbito de la educación indígena, no se menciona nada de los pueblos afromexicanos, ni de la interculturalidad para todos. Aunque en la estrategia correspondiente a la reforma curricular de la educación básica, sí aparezca como parte de los rasgos del tipo de educación a promover. Habrá que seguir la pista en la idea de un nuevo capitulo para la incorporación de la educación intercultural y la interculturalidad en la educación básica mexicana.

\section{CIERRE Y APERTURA}

Las políticas educativas hasta ahora abordadas, denotan dos elementos importantes de deconstruir en aras de proponer acciones que mejoren la relación político educativa de cara a la diversidad étnica, cultural y lingüística del país, después de observar su desplazamiento como política curricular. En primer lugar, admitir que continuar sólo con una lógica de las ciencias de la educación en el diseño, implementación y evaluación de políticas, no se solucionarán los grandes problemas que atañen a la interculturalidad como son el combate al racismo y la discriminación por condición étnica, cultural y lingüística, y segundo, asumir que atender la diversidad con políticas específicas para cada colectivo social es una fragmentación de lo nacional o bien mera acción afirmativa, pero hacerlo desde una visión generalizada-esencializada de los diferentes colectivos o movimientos sociales también es una visión distorsionada de la inclusión. El curriculum de la educación básica debe cambiar sus bases epistemológicas mediante la reinterpretación de las finalidades de este nivel, superando los fundamentos epistémicos que no funcionan más.

La intención es entender desde una lógica política, la necesidad de representación de todos los colectivos sociales en el sujeto pedagógico del curriculum nacional de la educación básica, ello supone otra bases para la acción política tanto gubernamental como de la sociedad civil, en particular del movimiento indígena y de los pueblos afrodescendientes mexicanos. 
El primer paso es asumir una aproximación intercultural de hacer política educativa, por lo tanto, es necesario asegurar la exigibilidad jurídica para que las comunidades puedan dar voz a lo que es culturalmente relevante aprender en cada uno de sus territorios y en segundo situar qué de los conocimientos y valores de los pueblos indígenas y afromexicanos deben aprender toda la niñez que cursa este nivel educativo.

La meta es complicada porque como se ha explicado antes, las reformas curriculares al mantener una racionalidad instrumental, temas como la interculturalidad para todos son tan problemáticos que se prefiere abandonar el término o regresar a que es un asunto solo para los pueblos indígenas, de ahí que la condición de tema emergente no esté signado por el tiempo sino por su capacidad de irrumpir y dislocar al curriculum de la educación básica mexicana.

\section{REFERENCIAS}

ARDITI, Benjamín. Rastreando lo político. En Revista de estudios políticos, núm. 87, enero-marzo de 1995, pp. 333-351.

BUENFIL, Rosa Nidia. Análisis de discurso y educación. México: Departamento de Investigaciones EducativasCINVESTAV.

COLL, César, POZO, J., SARABIA, B. y VALLS, E. Los contenidos en la reforma. Barcelona: Santillana-Aula XXI.1994.

DE ALBA, Alicia. Teoría y educación: en torno al carácter científico de la educación. México: Centro de Estudios sobre la Universidad de la UNAM, 1990.

DE ALBA, Alicia. Curriculum: crisis, mito y perspectivas. México: Centro de Estudios sobre la Universidad de la UNAM, 1991

DE ALBA, Alicia. Curriculum universitario. Académicos y futuro. México: UNAM/ Plaza y Valdés, 2002.

DÍAZ BARRIGA, Ángel. La educación en valores: Avatares del curriculum formal, oculto y los temas transversales. En Revista Electrónica de Investigación Educativa. 2006. Núm. 1, vol. 8, pp. 1-15. Consultado el día 12 de marzo de 2020 en: http://redie.uabc.mx/vol8no1/contenido- diazbarriga2.html

DÍAZ BARRIGA, Ángel y GARCÍA GARDUÑO, José María. Desarrollo del curriculum en América Latina: experiencias en 10 países. Buenos Aires: Miño y Dávila, 2014.

Follari, Roberto. Filosofía y educación: nuevas modalidades de una vieja relación. En DE ALBA, Alicia. Teoría y educación: en torno al carácter científico de la educación. México: Centro de Estudios sobre la Universidad de la UNAM, 1990. Pp.66-77.

FOUCAULT, Michel. Nietzche, la genealogía, la historia. Valencia: Pre-textos, 1988.

FOUCAULT, Michel. La verdad y las formas jurídicas. Barcelona: Gedisa editorial, 1996.

FURLÁN, Alfredo. Ideología del discurso curricular. México: Universidad Autónoma de Sinaloa / Universidad Nacional Autónoma de México, 1997.

GALLARDO, Ana Laura. Racismo y discriminación en el sistema educativo mexicano. Claves desde las reformas a la educación básica nacional en el siglo XXI (2006 y 2011). Tesis de doctorado. 2014. Programa de maestría y doctorado en Pedagogía, Universidad Nacional Autónoma de México, México, 2014.

GOBIERNO FEDERAL. Acuerdos de San Andrés Larráinzar: derechos y cultura indígena. México: Diario Oficial de la Federación, 1996.

HABERMAS, Jürguen. Conocimiento e interés. Madrid: Taurus, 1982.

JUÁREZ, Benito. Manifiesto a la Nación. México: s/r, 1859. 
ISSN 1983-1579

Doi: 10.22478/ufpb.1983-1579.2020v13n1.51546

http://periodicos.ufpb.br/ojs2/index.php

LACLAU, Ernesto y MOUFFE, Chantal. Hegemonía y estrategia socialista: hacia una radicalización de la democracia. Madrid: Siglo XXI,1987.

LATAPÍ, Pablo. La moral regresa a la escuela. México: CESU-UNAM, 1999.

NIETZCHE, Friedrich. Genealogía de la moral. Madrid: Alianza, 2011.

OROZCO, Bertha. El cambio curricular en la facultad de enfermería de la UASLP. Una mirada a su historia discontinua. Tesis de doctorado. 2015. Programa de maestría y doctorado en Pedagogía, Universidad Nacional Autónoma de México, México, 2015.

PND. Plan Nacional de Desarrollo 2019-2024. México: Gobierno de la República, 2019.

POPKEWTIZ, Thomas. Sociología política de las reformas educativas. Madrid: Morata, 1991.

PUIGGRÓS, Adriana. Modernidad, posmodernidad y educación en América Latina. En De Alba, Alicia (comp.). Posmodernidad y educación. México: Centro de Estudios sobre la Universidad, 1995, pp. 178-202.

SÁNCHEZ PUENTES, Ricardo. La investigación científica en ciencias sociales (Estructura dialogal, campo de lucha ideológica y factor del proyecto ético-político de una comunidad). En Revista Mexicana de Sociología. Vol. 46, No. 1, Ene. - Mar., 1984, pp. 129-160.

SCHMELKES, Sylvia. La formación de valores en la educación básica. México: SEP, 2004.

SECRETARÍA DE EDUCACIÓN PÚBLICA (SEP). Acuerdo Nacional para la Modernización Educativa. México: SEP,1992.

SECRETARÍA DE EDUCACIÓN PÚBLICA (SEP). Modelo educativo. Primaria. México: SEP,1993.

SECRETARÍA DE EDUCACIÓN PÚBLICA (SEP). Programa Sectorial de Educación 2007-2012. México: SEP,2006.

SECRETARÍA DE EDUCACIÓN PÚBLICA (SEP). Acuerdo Secretarial 384 por el que se establece el nuevo Plan y Programas de Estudio para Educación Secundaria. México: Diario Oficial de la Federación, 2006a.

SECRETARÍA DE EDUCACIÓN PÚBLICA (SEP). Plan de estudios 2011: Educación Básica. México: Dirección General de Desarrollo Curricular, 2011.

SEGOB. Constitución Política de los Estados Unidos Mexicanos. México: Secretaría de Gobernación, 2019.

TABA, Hilda. Elaboración del currículo, teoría y práctica. Buenos Aires: Troquel, 1976.

TYLER, Ralph. Principios básicos del currículo. Buenos Aires: Troquel, 1973.

Recebido em: 30 de março de 2020

Aceito em: 19 de abril de 2020

Publicado em: 25 de abril de 2020 